\title{
Cesium Incorporation in Hollandite-rich Multiphasic Ceramic Waste Forms
}

\author{
P. Tumurugoti*, ${ }^{\text {, B. M. Clark }}{ }^{1}$, D. J. Edwards ${ }^{2}$, Jake Amoroso ${ }^{3}$ and S. K. Sundaram \\ ${ }^{1}$ Kazuo Inamori School of Engineering, The New York State College of Ceramics, Alfred University, \\ Alfred, NY 14802 \\ ${ }^{2}$ Pacific Northwest National Laboratory, Richland, WA 99352 \\ ${ }^{3}$ Savannah River National Laboratory, Aiken, SC 29808
}

\begin{abstract}
Hollandite-rich multiphase waste form compositions processed by melt-solidification and spark plasma sintering (SPS) were characterized, compared, and validated for nuclear waste incorporation. Phase identification by x-ray diffraction (XRD) and electron back-scattered diffraction (EBSD) confirmed hollandite as the major phase present in these samples along with perovskite, pyrochlore and zirconolite. Distribution of selected elements observed by wavelength dispersive spectroscopy (WDS) maps indicated that Cs formed a secondary phase during SPS processing, which was considered undesirable. On the other hand, Cs partitioned into the hollandite phase in melt-processed samples. Further analysis of hollandite structure in melt-processed composition by selected area electron diffraction (SAED) revealed ordered arrangement of tunnel ions $(\mathrm{Ba} / \mathrm{Cs})$ and vacancies, suggesting efficient $\mathrm{Cs}$ incorporation into the lattice.
\end{abstract}

Keywords: Ceramic waste forms, Hollandite, Melt-processing, SPS, Cs partitioning, Microstructure.

\section{Introduction}

Long-term safe disposal of radioactive wastes generated from commercial nuclear power plants and weapons program is one of the industry's biggest present day challenges. In a once-through nuclear fuel cycle, the fuel is used until its energy output becomes economically impractical at which point the used nuclear fuel (UNF) is transferred to an interim cooling and storage facility prior to eventual disposal in a geological repository. In a closed fuel cycle, the UNF is reprocessed prior to disposal to extract unreacted 
' $\mathrm{U}$ ' and 'Pu' for reuse. The aqueous reprocessing of UNF generates high-level waste (HLW) that is comprised of a wide range of radioactive elements including minor actinides (e.g., $\mathrm{Np}, \mathrm{Am}, \mathrm{Cm}$ ), fission products $\left({ }^{135} \mathrm{Cs},{ }^{129} \mathrm{I},{ }^{99} \mathrm{Tc}\right)$ and many other non-radioactive elements. Some of these radionuclides have half-lives of millions of years and must be separated and immobilized in a suitable material that will retain those radionuclides for extended periods of time in a geologic repository [1]. In general, the waste elements are immobilized in durable matrices - glasses, cement and concrete, ceramics or glass-ceramics - before disposal in geological depository [2]. Ideal requirements [3] for waste forms include high chemical durability, high radiation resistance, long-term thermodynamic stability, mechanical integrity, appropriate thermal conductivity, homogeneous distribution of radionuclides, low-temperature processing to reduce the volatility of elements like Cs, and long-term compatibility with geological environment. Immobilization of HLW in borosilicate glasses is the most popular practice. The technology for industrial scale vitrification of radioactive wastes has been well-established. Borosilicate glass waste forms can accommodate a wide range of radionuclide sizes into their random network. However, devitrification of glasses under extreme conditions poses a threat to the structural stability of the glass, enhancing the leachability of the glasses, which could potentially result in the release of radioactive hazardous elements [4].

Multiphase ceramic materials for nuclear waste immobilization were proposed in 1970s [5-7]. The basic idea emerged from the natural mineral rock isomorphs that could accommodate wide range of radioactive elements. Synroc (Synthetic Rock), a titanate-based multiphase ceramics, was developed by Ringwood and coworkers in 1978 [6, 7]. Since then, different chemical formulations of Synroc materials have been reported in the literature over the years based on the composition of HLW for corresponding waste immobilization. Synroc-C, a Synroc variation, is a multiphase mixture of different titanates, which has been designed to incorporate radioactive waste from commercial nuclear power plants. Major phases in Synroc-C include hollandite, perovskite, zirconolite, and pyrochlore. Hollandite phase is specifically targeted to accommodate Cesium (Cs), whereas perovskite, zirconolite and pyrochlore phases host other 
waste elements, lanthanides and minor actinides. Cs is one of the major fission products in HLW that exists as short-lived radionuclides $\left({ }^{134} \mathrm{Cs}\right.$, ${ }^{136} \mathrm{Cs}$ and $\left.{ }^{136} \mathrm{Cs}\right)$, long-lived radionuclides $\left({ }^{135} \mathrm{Cs}\right)$, and nonradioactive isotopes $\left({ }^{133} \mathrm{Cs}\right)[1]$. The amount of Cs is limited by the presence of short-lived Cs isotopes which, during the first few centuries, generate high amounts of heat in the surrounding material and radiotoxicity. In addition, $\mathrm{Cs}^{+}$ions are highly mobile in aqueous medium and can form $\mathrm{Cs}$-rich parasitic phases affecting the waste form durability [1]. Hence the composition of Synroc C is designed to selectively immobilize Cs into hollandite phase. Our present study emphasizes Cs-substitution in hollandite and its microstructural characterization.

\section{Synroc: Phase Assemblage}

The general formula for Synroc hollandites is $\left[\mathrm{Ba}_{x} \mathrm{Cs}_{y}\right]\left[M{ }^{3+}{ }_{2 x+y} \mathrm{Ti}_{8-2 x-y}\right] \mathrm{O}_{16}$, where $M^{3+}$ is a trivalent cation [8]. The structure consists of a continuous network of edge sharing and corner sharing $(\mathrm{M}, \mathrm{Ti}) \mathrm{O}_{6}$ octahedra resulting in large tunnels that accommodate heavier elements like Cs and $\mathrm{Ba}$ [9-12]. Depending on the trivalent cation, it can adapt a tetragonal symmetry (I4/m space group) or a monoclinic symmetry $(\mathrm{I} 2 / \mathrm{m})$ with the tunnels parallel to c-axis or b-axis, respectively. Tunnels in barium hollandites are only partially occupied and the occupants, $\mathrm{Ba} / \mathrm{Cs}$, are ordered giving rise to supercell structures [11, 13, 14]. Cs cannot substitute all Ba atoms in hollandite lattice because of size constraints $\left(r_{C s^{+}} \sim 1.8 \dot{A}>\right.$ $\left.r_{B a^{2+}} \sim 1.5 \dot{A}\right)$. However it has been shown that pure Cs-hollandites can be prepared under certain reducing conditions, where significant amount of $\mathrm{Ti}^{4+}\left(r_{T i^{4+}} \sim 60 \mathrm{pm}\right)$ is reduced to larger $\mathrm{Ti}^{3+}\left(r_{T i^{3+}} \sim 67 \mathrm{pm}\right)$ to increase the tunnel size $[8,14]$. The extent of structural distortions introduced by substituting $\mathrm{Ti}^{4+}$ by a trivalent cation determines the occupancy ratio $\mathrm{Ba} / \mathrm{Cs}$ in the tunnels and unit cell dimensions in hollandites. In addition, synroc hollandite composition is intended to accommodate the structural changes when radioactive $\mathrm{Cs}^{+}$undergoes transmutation. $\beta$-decay of $\mathrm{Cs}^{+}$results in the formation of $\mathrm{Ba}^{2+}$ and electron $\left(\mathrm{Cs}^{+} \rightarrow \mathrm{Ba}^{2+}+\beta^{-}\left(\mathrm{e}^{-}\right)\right)$which is absorbed by $\mathrm{Ti}^{4+}$ to form $\mathrm{Ti}^{3+}$ [10]. Other phases of interest perovskite, pyrochlore and zirconolite - are not specific to particular element(s). In Synroc, titanate perovskites analogous to $\mathrm{CaTiO}_{3}$ are predominantly formed. Perovskites are capable of accommodating 
wide range of cation combinations that can satisfy the cation radii ratio and charge neutrality [15]. Relevant to the chemistry of the waste stream, $\mathrm{Ca}^{2+}$ could be replaced by $\mathrm{Sr}^{2+}, \mathrm{Ba}^{2+}$ and trivalent rareearth elements while $\mathrm{Ti}^{4+}$ could be replaced by $\mathrm{Nb}^{5+}, \mathrm{Mo}^{4+}, \mathrm{U}^{4+}, \mathrm{Pu}^{4+}, \mathrm{Cr}^{3+}, \mathrm{Fe}^{3+}, \mathrm{Al}^{3+}$ etc.[6]. Zirconolite and pyrochlore phases are the major hosts for minor actinides and other rare-earth elements [16].

Simulated waste forms have been processed by different processing methods, e.g., conventional sintering[10], hot isostatic pressing (HIP)[17], melting and solidification [18-20], and spark plasma sintering (SPS)[19]. Each process, depending on the composition and process variables, would potentially result in a distinctly different microstructure, which could affect the waste form performance, e.g., chemical durability and radiation resistance. In additiona, morphological features like porosity and secondary parasitic phases can adversely affect the performance of waste forms produced. In this study, we prepared simulated waste forms by melt-processing and SPS. Melt-processing is a relatively simple method where the pre-mixed stoichiometric amounts of precursor materials are heated to melting temperature and cooled back slowly to form crystalline multi-phase ceramics. The existing glass-melting technology used in vitrification of HLW offers an advantage in developing melt-processing for high throughput of waste forms. Limited literature is available on the characteristics of melt-processed ceramic waste forms $[18,21,22]$. SPS is of interest owing to the short sintering cycles needed for the development of phase assemblage. The short processing times can suppress the losses of volatile waste elements such as Cs. High densification is achieved through simultaneous application of uniaxial pressure and DC current to a graphite die containing the powder sample. Resistive heating of the graphite die generates fast heating rates of up to $1000^{\circ} \mathrm{C} / \mathrm{min}$. Contact with graphite die also exposes the samples to carbon contamination and reducing conditions during processing.

The present paper summarizes results of our study of Cs incorporation and microstructure evolution in Synroc-based multiphase ceramic waste forms. We present the microstructures and processing effects on phase distribution and elemental segregation. This work is an extension of our previously published results on the microstructures of the same compositions processed by the same 
methods [19]. The present paper focuses on Cs partition and distribution in hollandite phase and the resultant tunnel ion ordering in the lattice, when processed as a multiphase waste form.

\section{Experimental}

\subsection{Processing}

Savannah River National Laboratory (SRNL) developed the multiphase composition used in this study. The compositional design was based on simulated waste stream compositions developed under the Department of Energy (DOE) Fuel Cycle Research and Development (FCR\&D) program and reported elsewhere $[18,23,24]$. The intended target phases are hollandite, perovskite, zirconolite, and pyrochlore. Constituent oxides and carbonates were mixed in stoichiometric amounts, ball-milled in deionized water, and force dried in air at $90^{\circ} \mathrm{C}$. The resultant mixture was used as the starting material for waste form processing.

\section{Melt-Processing}

Melt-processing of small batches of material was done in an electrically heated tube furnace. Approximately $10 \mathrm{~g}$ of the starting material, loosely packed in a $\mathrm{Pt}$ foil, was heated to $1500^{\circ} \mathrm{C}$ at a rate of 5 $\mathrm{K} / \mathrm{min}$, held for 30 minutes, and furnace-cooled back to room temperature. The solidified material was removed from the foil and used for characterization.

\section{Spark Plasma Sintering}

Reactive SPS was carried out using a FCT HP D 25 (FCT Systeme GmbH, Rauenstein, Germany) furnace with graphite dies and punches. A schematic description of the die setup is reported elsewhere [25]. The unreacted starting powder $(\sim 3 g)$ enclosed within a thin graphite foil was placed inside a graphite die. The reactive sintering was performed under a pressure of $54 \mathrm{MPa}$ by heating the die set-up to a maximum temperature of $1000^{\circ} \mathrm{C}$ at a heating rate of $100 \mathrm{~K} / \mathrm{min}$, holding for 3 minutes, and cooling back at a rate of $100 \mathrm{~K} / \mathrm{min}$. 


\subsection{Characterization}

Scanning electron microscopy (SEM) and electron back-scattered diffraction (EBSD) studies were performed using a high-resolution JEOL 7600F (JEOL Ltd., Tokyo, Japan) field-emission SEM equipped with a Nordlys detector (Oxford Instruments, UK) for EBSD, complete with the HKL Channel5 software package and, a low-angle backscatter electron (LABE) to collect Kikuchi diffraction patterns. Further phase assemblage and elemental distribution were studied by wavelength dispersive spectroscopy (WDS). Selected elemental maps from multiphase regions, identified from back-scattered electron (BSE) images, were collected using JEOL JXA-8200, WD/ED Combined Electron Probe Microanalyzer (EPMA) (JEOL Ltd., Tokyo, Japan). Elemental scans were performed at an accelerating potential of $15 \mathrm{kV}$, with a step size of $0.5 \mu \mathrm{m}$ in $x$-and $y$-directions, and a dwell time of 80 milliseconds at each point.

Electron-transparent samples for transmission electron microscope (TEM) analysis were prepared using DualBeam ${ }^{\mathrm{TM}}$ FEI Strata 400 focused ion beam (FIB) microscope (FEI, Hillsboro, USA) equipped with Omniprobe. Since hollandite is the phase of interest, a region with coarse hollandite grains on the surface was selected. A fragment $\sim 10 \mu \mathrm{m}$ deep and a lateral cross section of $\sim 20 \times 3 \mu \mathrm{m}^{2}$ was pulled out, which was further ion-milled on hollandite phase until electron-transparent area was obtained. Selected area electron diffraction (SAED) patterns and high-resolution lattice images were collected using F20 Tecnai (FEI, Hillsboro, USA) field emission TEM at an operating voltage of 200kV.

\section{Results and Discussions}

The composition used in this study is hereafter indicated as CAF-MP and the corresponding meltprocessed and SPS processed variants by CAF-MP-Melt and CAF-MP-SPS respectively. As-prepared CAF-MP-Melt had a characteristic melt-solidified structure as evident from the wetting of Pt foil. There was minimal chemical reaction with the Pt as the sample could easily be removed from the foil. CAF-MPSPS sample was relatively strong and dense, as typical of SPS processed material. The measured bulk density was relatively high $\left(4.64 \mathrm{~g} / \mathrm{cm}^{3}\right)$ compared to that of CAF-MP-Melt $\left(4.07 \mathrm{~g} / \mathrm{cm}^{3}\right)$. As mentioned in 
our previous work [19], initial phase identification of these materials showed that hollandite was the major phase followed by perovskite and pyrochlore/zirconolite along with small amounts of $\mathrm{TiO}_{2}$. Microstructures of SPS and melt samples are shown in Figure 1. Although it was initially presumed that this could be the excess or unreacted $\mathrm{TiO}_{2}$ [19], our recent study showed that during melt-processing, rutile is one of the final phases recrystallized during solidification of CAF-MP [20]. CAF-MP-Melt exhibited the typical melt-solidified microstructure - large grains of different phases and large pores trapped between growing phases - while CAF-MP-SPS exhibited less porosity and a fine-grained microstructure. The SPS microstructure can be seen as a matrix of hollandite phase with small islands of other distributed phases. To confirm the phase identification and to study the microstructural phase distribution, EBSD analysis was performed. Electron back-scattered patterns (EBSP) or Kikuchi bands collected from different phases matched with the phases identified from x-ray diffraction.
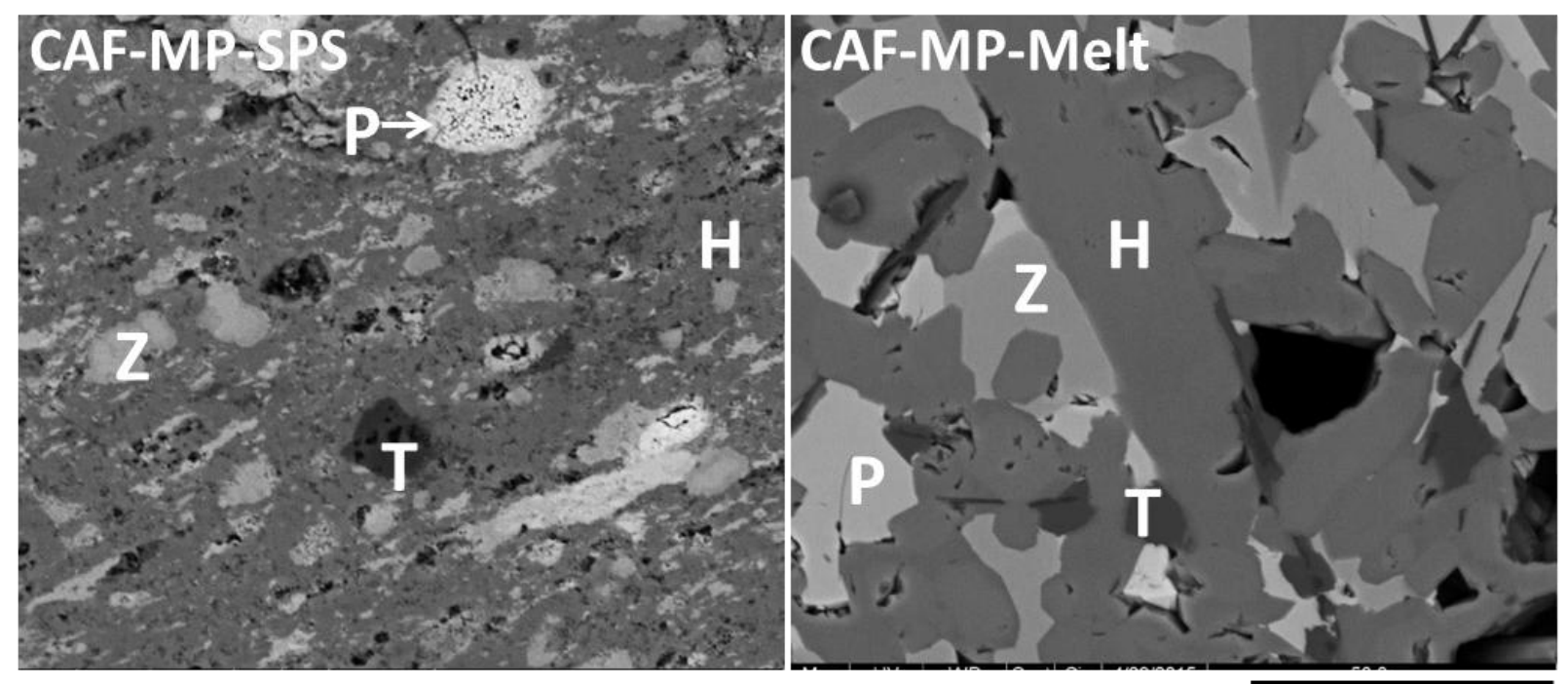

$50 \mu \mathrm{m}$

Figure 1: Back-scattered images of CAF-MP-SPS and CAF-MP-Melt $\quad(\mathrm{H}=$ Hollandite, $\mathrm{P}=$ Perovskite $\mathrm{Z}=$ Pyrochlore/Zirconolite, and $\mathrm{T}=\mathrm{TiO}_{2}$ ).

Figure 2 shows the band contrast maps and phase maps for SPS and melt-processing samples. In addition to hollandite and perovskite in CAF-MP-SPS, unreacted $\mathrm{CeO}_{2}$ was seen segregated and 
coexisting with pyrochlore or zirconolite phase. In Synroc-based formulations, $\mathrm{Ce}^{4+}$ or $\mathrm{Pu}^{4+}$ partitions into Nd-rich pyrochlore or zirconolite phases. This SPS microstructure can thus be interpreted as an ongoing transformation of $\mathrm{CeO}_{2}$ and provided enough time, total $\mathrm{Ce}^{4+}$ in the composition would have substituted into the pyrochlore lattice. EBSD maps together with BSE images reveal the microstructural development of SPS samples. Although the visual and microstructural examination indicated no bulk melting, there is a clear implication of mass transport occurring within the samples during the sintering process. Phase distribution maps of CAF-MP-SPS shows that the zones rich in perovskite and pyrochlore are randomly distributed in the hollandite-rich matrix and each zone in turn is polycrystalline. Detailed description of diffusion mode or sintering mechanism during SPS is beyond the scope of this study.

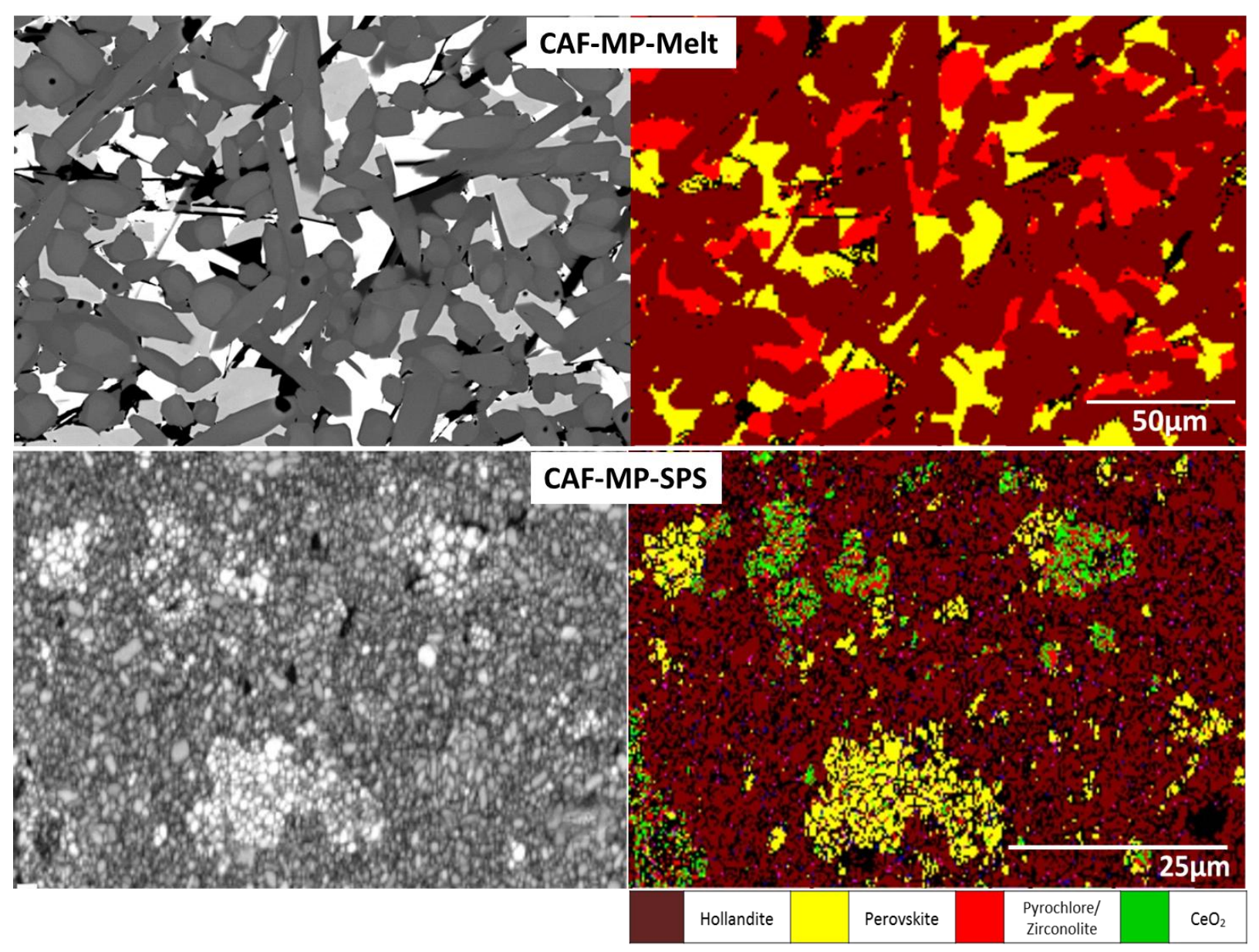

Figure 2: Phase maps obtained from EBSD 
Figure 3 shows the WDS maps of selected elements in CAF-MP-Melt. Hollandite, the major phase, consisted of primarily $\mathrm{Ba}, \mathrm{Cr}, \mathrm{Fe}$, Ti and $\mathrm{Cs}$. While $\mathrm{Ba}$ and $\mathrm{Cs}$ are homogeneously distributed, $\mathrm{Cr}$ and Fe have compositional gradients across individual grains, as seen in Figure 3. Cr content is the highest at the core and diminishes towards the edges of the grains, whereas Fe has the exact opposite trend. The cause of this $\mathrm{Cr}$ and $\mathrm{Fe}$ segregation is not well understood yet. We attribute this to the competition between $\mathrm{Fe}$ and $\mathrm{Cr}$ for the oxygen within the grains. $\mathrm{Ca}$ is seen in both perovskite and pyrochlore phases but $\mathrm{Zr}$ is partitioned preferentially into pyrochlore phase.

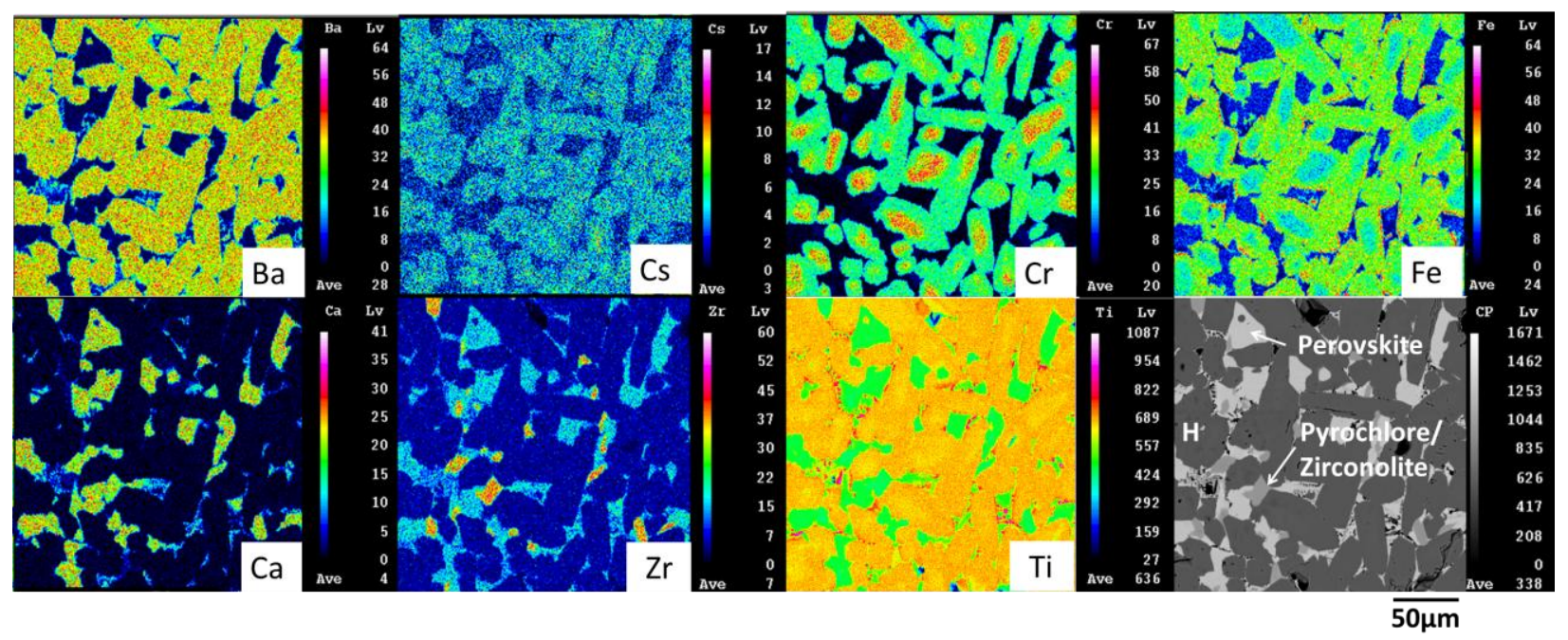

Figure 3: WDS maps of selected elements of CAF-MP-Melt

The elemental maps of CAF-MP-SPS sample shown in Figure 4 do not provide the same individual phases resolution (owing to the grain size differences among processes) as for the meltprocessed sample but nevertheless provide key information. $\mathrm{Ba}$ and $\mathrm{Cr}$ can be used to identify the hollandite phase and are distributed throughout. Cs-rich regions were observed in the WDS maps and do not correspond to the $\mathrm{Ba}$ and $\mathrm{Cr}$ maps. Although the exact chemistry and crystal structure of these Cs-rich phases are not known, they are generally considered undesirable for waste form application due to higher propensity to $\mathrm{Cs}$ attack by water on exposure. The maps confirm that the perovskite (Ca- and Nd-rich regions) and pyrochlore (Zr-rich) phases have appropriate targeted elements in the samples. 


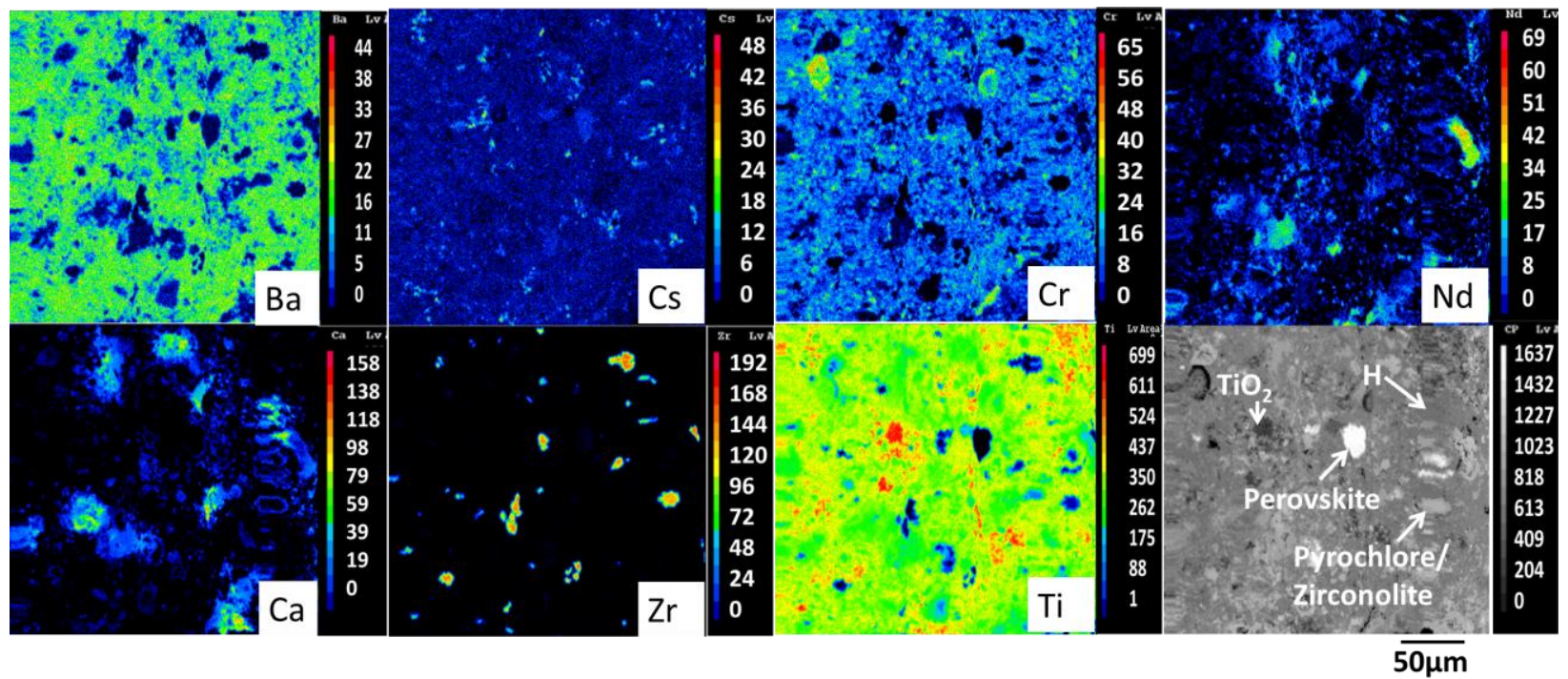

Figure 4: WDS maps of selected elements of CAF-MP-SPS

TEM observation of FIB milled samples was performed to investigate the hollandite phase further. Since SPS samples were found not to have Cs incorporated into the hollandite lattice, TEM of CAF-MP-SPS was not performed in this study. SAED patterns collected from a hollandite region of CAF-MP-Melt could be indexed using monoclinic (I2/m) unit cell structural model [26]. Figure 5 shows the FIB milled fragment, hollandite lattice, and the corresponding electron diffraction pattern along [011] zone axis in Figure 5(a), 5(b), and 5(c) respectively. In addition to the strong Bragg reflections resulting from the octahedral framework shown in Figure 5c, diffuse spots and streaks of low-intensity reflections can be seen. These additional satellite reflections are common in modulated structures and, in general, result from planar defects like stacking faults, twinning or compositional modulations [27, 28]. In case of barium hollandites, the presence of these reflections is generally attributed to compositional modulations. 


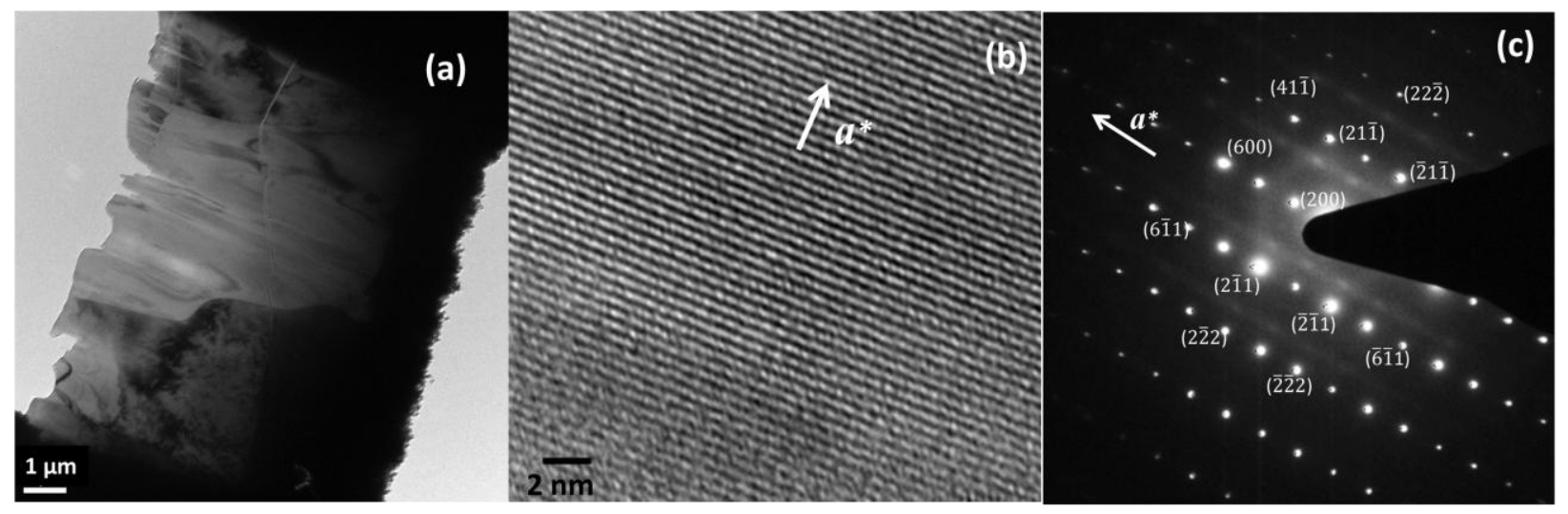

Figure 5: (a) FIB-milled CAF-MP-Melt sample used for TEM observation, (b) Hollandite lattice as viewed form [011] zone axis, and (c) the corresponding SAED pattern

The hollandite compositions for waste forms are typically designed in such a way that only a fraction of tunnel sites is occupied by $\mathrm{Ba} / \mathrm{Cs}$. It has been widely reported that the cations/vacancies adopt an ordered arrangement within the tunnels forming superlattice structures [11, 13, 29-31]. Along with this intratunnel ordering, in many cases, intertunnel correlation also exists resulting in three-dimensional modulated structures. This has been demonstrated by comprehensive electron diffraction analysis as reported in several works $[10,11,32]$. While the Bragg spots can be indexed by integral multiples of reciprocal lattice vectors $\boldsymbol{a}^{*}, \boldsymbol{b}^{*}$ and $\boldsymbol{c}^{*}$, satellite reflections are described by the nature of modulation [27, 33]. In the SAED pattern shown in Figure 5(c), the satellite reflections and diffuse streaks run parallel to $\boldsymbol{a}^{*}$ as indicated and lie in the plane of $\boldsymbol{a}^{*}$ and $\boldsymbol{b}^{*}-\boldsymbol{c}^{*}$. Comparing it to the similar reported SAEDs [10, 11] it can be understood that there is compositional modulation in three-dimensions. That is, ordering of cations along the tunnels together with intertunnel correlation in the hollandite lattice. Due to the limited degree of rotation of the FIB sample, SAED patterns along the principal axes could not be collected and hence, modulations or multiplicities along different directions could not be analyzed in detail. Nevertheless, our data suggests that the hollandite lattice in melt-processed multiphase waste form has three-dimensional ordering of $\mathrm{Ba}, \mathrm{Cs}$ and/or vacancies. It is to be noted that the location of satellite reflections or the distribution of modulation vectors is sensitive to the local composition. Different 
crystallites can have different degrees of ordering of tunnel ions resulting in different multiplicities [34].

It is also important to consider the implications on the performance of these materials as a waste form. Ba and Cs sites are typically enclosed in a box-shaped network of eight oxygen atoms. When Ba ions along the tunnels are replaced by larger Cs ions, local deformation occurs that has to be compensated by the surrounding tunnel sites to maintain lattice stability. Hence, Cs ions tend to occupy isolated sites rather than sites next to occupied $\mathrm{Ba} / \mathrm{Cs}$ sites and adapt an ordered arrangement with $\mathrm{Ba}$ ions resulting in superstructures $[14,35]$. These superstructures can result in an increased activation barrier for Cs ions migrating to the adjacent tunnel sites [30].

\section{Conclusion}

Hollandite-rich waste forms prepared by melt-processing and SPS were observed to have similar phase assemblage - hollandite, perovskite, pyrochlore-zirconolite - as supported by XRD and EBSD data. In SPS processed samples, small amounts of unreacted $\mathrm{CeO}_{2}$ was detected from EBSD phase maps. Cs partitioning into the hollandite phase, a primary investigation of this study, was observed only for meltprocessed sample. SPS processing resulted in separation of Cs-rich phases. Detailed electron diffraction patterns from melt-processed sample revealed superlattice reflections indicating an ordered arrangement of tunnel cations, $\mathrm{Ba}$ and $\mathrm{Cs}$, and vacancies, resulting in a three-dimensional modulated structure. Our results suggest that melt-processing of waste forms can generate desirable microstructures and hence, can be considered as a potentially promising method for producing durable ceramic waste forms.

\section{Acknowledgements:}

The authors acknowledge the financial support from the Department of Energy (DOE), Nuclear Energy University Program (NEUP). This work made use of the electron microscopy facility of the Cornell Center for Materials Research (CCMR) with support from the National Science Foundation Materials Research Science and Engineering Centers (MRSEC) program (DMR 1120296). Acknowledgements are 
also due to Gerry Wynick for help with WDS work. BMC is supported by the NEUP fellowship. SKS acknowledges support from the Kyocera Corporation in the form of Inamori Professorship.

\section{References}

[1] D. Caurant, P. Loiseau, O. Majerus, V. Aubin-Chevaldonnet, I. Bardez, A. Quintas, Glasses, glassceramics and ceramics for immobilization of highly radioactive nuclear wastes. Nova Science Publishers New York, 2009.

[2] I.W. Donald, B.L. Metcalfe, R.N.J. Taylor, J. Mater. Sci. 32 (1997) 5851-5887.

[3] S.V. Stefanovsky, S.V. Yudintsev, R. Gieré, G.R. Lumpkin, Geological Society, London, Special Publications 236 (2004) 37-63.

[4] G.J. McCarthy, W.B. White, R. Roy, B.E. Scheetz, S. Komarneni, D.K. Smith, D.M. Roy, Nature 273 (1978) 216-217.

[5] G.J. McCarthy, Nucl. Technol. 32 (1977) 92-105.

[6] A. Ringwood, S. Kesson, N. Ware, W. Hibberson, A. Major, Geochem. J. 13 (1979) 141-165.

[7] A.E. Ringwood, S.E. Kesson, N.G. Ware, W. Hibberson, A. Major, Nature 278 (1979) 219-223.

[8] S.E. Kesson, T.J. White, Proc. R. Soc. London, Ser. A 405 (1986) 73-101.

[9] W. Sinclair, G. McLaughlin, A. Ringwood, Acta Crystallogr. Sect. B: Struct. Sci. 36 (1980) 29132918.

[10] V. Aubin-Chevaldonnet, D. Caurant, A. Dannoux, D. Gourier, T. Charpentier, L. Mazerolles, T. Advocat, J. Nucl. Mater. 366 (2007) 137-160.

[11] S.E. Kesson, T.J. White, Proc. R. Soc. London, Ser. A 408 (1986) 295-319.

[12] R.W. Cheary, J. Kwiatkowska, J. Nucl. Mater. 125 (1984) 236-243.

[13] L. Bursill, J. Kwiatkowska, J. Solid State Chem. 52 (1984) 45-52.

[14] R.W. Cheary, Mater. Sci. Forum 27 (1988) 397-406.

[15] M. Pena, J. Fierro, Chem. Rev. 101 (2001) 1981-2018.

[16] G.R. Lumpkin, Elements 2 (2006) 365-372.

[17] Y. Zhang, H. Li, S. Moricca, J. Nucl. Mater. 377 (2008) 470-475.

[18] J. Amoroso, J.C. Marra, M. Tang, Y. Lin, F. Chen, D. Su, K.S. Brinkman, J. Nucl. Mater. 454 (2014) 12-21.

[19] B. Clark, P. Tumurugoti, S. Sundaram, J. Amoroso, J. Marra, K. Brinkman, Metallurgical and Materials Transactions E 1 (2014) 341-348.

[20] P. Tumurugoti, S. Sundaram, S.T. Misture, J.C. Marra, J. Amoroso, J. Nucl. Mater. 473 (2016) $178-188$. 
[21] J. Crum, V. Maio, J. McCloy, C. Scott, B. Riley, B. Benefiel, J. Vienna, K. Archibald, C. Rodriguez, V. Rutledge, J. Nucl. Mater. 444 (2014) 481-492.

[22] V. Maio, B. Benefiel, C. Scott, J. Crum, C. Rodriguez, J. Amoroso, J. Marra, (2015).

[23] P. Tumurugoti, S. Sundaram, K. Brinkman, J. Amoroso, K. Fox, Ceram. Trans. 250 (2014) $205-$ 212.

[24] J. Amoroso, J. Marra, S.D. Conradson, M. Tang, K. Brinkman, J. Alloys Compd. 584 (2014) 590599.

[25] B. Clark, S. Sundaram, K.S. Brinkman, K. Fox, J. Amoroso, Ceram. Trans. 250 (2014) 127-135.

[26] R.W. Cheary, Acta Crystallogr. Sect. B: Struct. Sci. 42 (1986) 229-236.

[27] M. De Graef, Introduction to conventional transmission electron microscopy. Cambridge University Press, 2003.

[28] J. Van Landuyt, G. Van Tendeloo, S. Amelinckx, Pure Appl. Chem. 57 (1985) 1373-1382.

[29] M.L. Carter, R.L. Withers, J. Solid State Chem. 178 (2005) 1903-1914.

[30] L. Bursill, G. Grzinic, Acta Crystallogr. Sect. B: Struct. Sci. 36 (1980) 2902-2913.

[31] F. Mijlhoff, D. Ijdo, H. Zandbergen, Acta Crystallogr. Sect. B: Struct. Sci. 41 (1985) 98-101.

[32] E. Fanchon, J. Hodeau, J. Vicat, J. Watts, J. Solid State Chem. 92 (1991) 88-100.

[33] U. Kolb, K. Shankland, L. Meshi, A. Avilov, W.I. David, Uniting Electron Crystallography and Powder Diffraction. Springer, 2012.

[34] A. Leinekugel-le-Cocq-Errien, P. Deniard, S. Jobic, E. Gautier, M. Evain, V. Aubin, F. Bart, J. Solid State Chem. 180 (2007) 322-330.

[35] R. Cheary, Acta Crystallogr. Sect. B: Struct. Sci. 43 (1987) 28-34. 


\title{
Cesium Incorporation in Hollandite-rich Multiphasic Ceramic Waste Forms
}

\author{
P. Tumurugoti*, ${ }^{\text {, B. M. Clark }}{ }^{1}$, D. J. Edwards ${ }^{2}$, Jake Amoroso ${ }^{3}$ and S. K. Sundaram \\ ${ }^{1}$ Kazuo Inamori School of Engineering, The New York State College of Ceramics, Alfred University, \\ Alfred, NY 14802 \\ ${ }^{2}$ Pacific Northwest National Laboratory, Richland, WA 99352 \\ ${ }^{3}$ Savannah River National Laboratory, Aiken, SC 29808
}

Table of contents figure with caption:

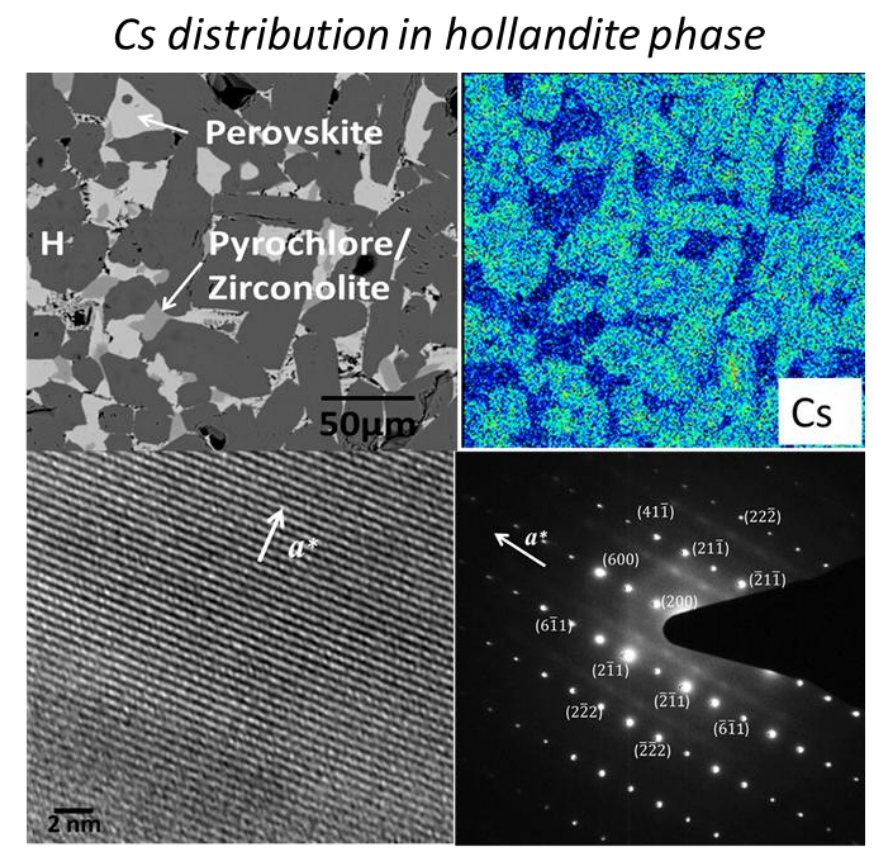

[011] zone axis diffraction pattern showing modulated structure 